\title{
Mineração
}

\section{Emprego de resíduos siderúrgicos e pellet feed minipelotizados na sinterização de minério de ferro}

\author{
Eduardo Reis de Oliveira \\ Engenheiro Metalúrgico \\ E-mail:eduardo@cefetes.br \\ Jader Martins \\ Prof. Dr. da UFOP \\ E-mail:jmartins@degeo.ufop.br
}

\section{Resumo}

Em metalurgia extrativa, a grande maioria dos processos de fabricação de ferro gusa nos altos-fornos usa como fonte de ferro minérios granulados e/ou aglomerados. O processo de sinterização foi projetado com o objetivo inicial do aproveitamento de minérios e combustíveis com granulometria inferiores a $6 \mathrm{~mm}$. Essas frações não podem ser utilizadas diretamente nos altos-fornos, por comprometerem a permeabilidade da carga, dificultando a passagem dos gases, condição imprescindível a um bom desempenho desse equipamento.

No processo convencional, toda a matéria-prima da sinterização é alimentada na forma de finos para a produção de sínter. A alternativa pesquisada foi a fabricação de minipelotas utilizando em sua composição resíduos siderúrgicos sólidos e de pellet feed, visando à substituição parcial do sinter feed por pellet feed. Para atingir tais objetivos, foram usados resíduos siderúrgicos, pellet feed alimentados na unidade de sinterização da empresa CST (Companhia Siderúrgica de Tubarão).

A metodologia de pesquisa foi formulada e experimentada visando à viabilidade técnica e econômica da proposta apresentada.

Palavras-chave: Resíduos siderúrgicos, aglomeração, minipelotas.

\begin{abstract}
Into extractive metallurgy, the large number of the processes of production of pig iron into the blast furnaces has used like iron search, granulated and/or agglomerated material. The sinterization process has designed with the initial purpose the use of ore and fuels with inferior granulometry than $6 \mathrm{~mm}$. These fractions can not be used directly into the blast furnace once they put in risk the permeability of the load, what becomes difficult the passage of the gases, indispensable condition in order to a good performance of this equipment.
\end{abstract}

Into the conventional process, all the raw material from the sinterization has been fed in the form of ore fines to the production of sinter. The researched alternative had been the production of mini-pellets that use in their composition solid residuals from steelmaking and pellet feed, trying the partial replacing of the sinter feed for pellet feed. In order to arrive such goals, steelmaking residuals and pellet feed that were fed into the unit of sinterization from the steelmaking enterprise CST (Companhia Siderúrgica de Tubarão).

The methodology of the research has been formulated and tried with the purpose of getting the technical and economical viability from this presented purpose.

Keywords: Residuals Steelmaking, agglomeration,minipellets 


\section{Introdução}

Nas últimas décadas, o mundo tem assistido ao aumento exponencial do custo da energia. Tem-se preocupado constantemente com as alterações produzidas no meio ambiente pelas grandes indústrias. Como consequiência, a reciclagem de resíduos é considerada, por vários setores industriais, como prática a contribuir para a minimização de tais problemas.

A presente dissertação trata da reciclagem dos pós e lamas da CST (Pereira, 1982), portadores de óxido de ferro e carbono minipelotizados com pelletfeed, que serão usados como componentes da mistura para sinterização, via pilha de homogeneização.

Não havendo problemas quanto à composição química desses materiais, as restrições relativas à granulometria e umidade deverão ser solucionadas pelo proposto projeto.

\section{Materiais e métodos}

\subsection{Levantamento dos materiais}

Os materiais sólidos finos gerados, ou subprodutos, com potencial de reciclagem em sinterização juntamente com o pellet feed foram identificados e amostrados. A hipótese assumida é que a carga constituída desses subprodutos, alimentada na sinterização em forma de mini-pelotas, não alteraria as especificações dos respectivos produtos e também não implicaria as características dos tipos de emissões (atmosféricas, líquidas e resíduos sólidos) geradas. A Tabela 1 mostra os tipos de materiais que foram utilizados no processo, a quantidade mensal gerada pela CST desses materiais, bem como a sua classificação quanto à sua característica aglomerante, sendo distribuídos os materiais em aglomerantes ou aglomerados.

\subsection{Descrição dos equipamentos utilizados}

Foram utilizados os seguintes equipamentos:

- Peneirador eletromagnético, produzido pela DENVER COMPANY, com um conjunto de peneiras de especificação ASTME-11-70.

- Misturador intensivo produzido pela empresa EIRICH, modelo R02, com capacidade para até 5,0 litros de material.
- Pelotizador de pneu com motor trifásico de $0,5 \mathrm{CV}$.

- Prensa para a medição da resistência mecânica fabricada pela KRATOS dotada de dinamômetro com capacidade para 10 quilogramas e precisão de 0,005 $\mathrm{kg} /$ pelota.

\subsection{Caracterização dos materiais}

As amostras foram caracterizadas quimicamente e granulometricamente com o objetivo de se conhecerem as suas características para o processo.

Foram realizadas 27 misturas para a fabricação das pelotas com as respectivas variáveis e níveis descritos abaixo:

- Tipos de aglomerantes - Os aglomerantes utilizados foram a RCAC e RCAL, que são materiais de características aglomerativas e são considerados resíduos da própria usina.

- Porcentagem de aglomerantes - Os aglomerantes foram utilizados nas proporções de 8,10 e $12 \%$, respectivamente, tendo como padrão a proporção de 10\% (Martins, 1980).

Tabela 1 - Materiais e respectivas quantidades disponíveis.

\begin{tabular}{c|c|c|c}
\hline Sigla & Descrição & Produção mensal (t) & Tipo \\
\hline PXCE & Pellet Feed & X & Aglomerado \\
\hline RLAA & Lama de aciaria & 5235 & Aglomerado \\
\hline RLIX & Lixo industrial & 6390 & Aglomerado \\
\hline RCAC & Calcário calcítico fino reciclado da calcinação & 4200 & Aglomerante \\
\hline RDLF & Dolomita fina reciclada da calcinação & 900 & Aglomerado \\
\hline RSUC & Escória de LD & 2616 & Aglomerado \\
\hline RCAL & Cal recuperada em despoeiramento & 3093 & Aglomerante \\
\hline RPOD & Pó de despoeiramento da Coqueria & 2076 & Aglomerado \\
\hline RPOF & Pó de balão de AF & 1656 & Aglomerado \\
\hline RBCV & Pó de balão de AF (carvão vegetal) & 1200 & Aglomerado \\
\hline
\end{tabular}

Onde $\mathbf{X}$ é a quantidade de material a ser determinada nesse trabalho.

Obs.: PXCE não é subproduto. 
Eduardo Reis de Oliveira et al.

- Porcentagem de Pellet Feed - Foram utilizados 40, 50 e $60 \%$ de Pellet Feed, respectivamente, sendo que $40 \%$ é a quantidade já usada com os rejeitos na granulometria gerada pela usina.

- Condições de cura - As condições de cura foram determinadas visando à reprodutibilidade industrial e à redução do custo de estocagem, sendo úmida na hora, seca e úmida ao tempo.
Além dos 27 testes citados anteriormente, foram realizados 3 testes brancos, ou seja, testes utilizando $0 \%$ de aglomerantes, variando as proporções de pellet feed em 40,50 e $60 \%$, respectivamente. O objetivo desses testes foi observar a interação aglomerativa dos materiais chamados, a princípio, de aglomerados. Também pode-se observar, através desse teste, a ação da distribui- ção granulométrica na resistência mecânica das pelotas. Com os materiais e as variâncias determinadas anteriormente, foi elaborada a tabela geral de testes ( $\mathrm{Ta}$ bela 2). As misturas selecionadas foram homogeneizadas em misturador intensivo e alimentarão o pelotizador com a finalidade de confecção de pelotas de 6 e $10,5 \mathrm{~mm}$, sendo que a propriedade testada foi a resistência a compressão.

Tabela 2 - Constituição das pelotas para cada teste.

\begin{tabular}{|c|c|c|c|c|c|c|c|c|c|c|}
\hline \multirow{2}{*}{ TESTE } & \multicolumn{10}{|c|}{ \% DOS CONSTITUINTES } \\
\hline & PXCE & RDLF & RLAA & RLIX & RPOD & RPOF & RSUC & RPOB & RCAC & RCAL \\
\hline 1 & 36,13 & 2,41 & 14,03 & 17,13 & 5,57 & 4,44 & 7,01 & 3,22 & 0,00 & 10,00 \\
\hline 2 & 36,19 & 2,41 & 14,03 & 17,13 & 5,57 & 4,44 & 7,01 & 3,22 & 10,00 & 0,00 \\
\hline 3 & 35,39 & 2,36 & 13,72 & 16,75 & 5,44 & 4,34 & 6,86 & 3,14 & 0,00 & 12,00 \\
\hline 4 & 35,39 & 2,36 & 13,72 & 16,75 & 5,44 & 4,34 & 6,86 & 3,14 & 8,00 & 0,00 \\
\hline 5 & 36,99 & 2,47 & 14,35 & 17,51 & 5,69 & 4,54 & 7,17 & 3,29 & 0,00 & 8,00 \\
\hline 6 & 36,99 & 2,47 & 14,35 & 17,51 & 5,69 & 4,54 & 7,17 & 3,29 & 8,00 & 0,00 \\
\hline 7 & 36,19 & 2,41 & 14,03 & 17,13 & 5,57 & 4,44 & 7,01 & 3,22 & 5,00 & 5,00 \\
\hline 8 & 36,99 & 2,47 & 14,35 & 17,51 & 5,69 & 4,54 & 7,17 & 3,29 & 4,00 & 4,00 \\
\hline 9 & 35,39 & 2,36 & 13,72 & 16,75 & 5,44 & 4,34 & 6,86 & 3,14 & 6,00 & 6,00 \\
\hline 10 & 46,19 & 0,00 & 12,21 & 17,51 & 5,69 & 4,54 & 2,56 & 3,29 & 0,00 & 8,00 \\
\hline 11 & 45,19 & 0,00 & 11,94 & 17,13 & 5,57 & 4,44 & 2,51 & 3,22 & 0,00 & 10,00 \\
\hline 12 & 44,18 & 0,00 & 11,68 & 16,75 & 5,44 & 4,34 & 2,45 & 3,15 & 0,00 & 12,00 \\
\hline 13 & 46,19 & 0,00 & 12,21 & 17,51 & 5,69 & 4,54 & 2,56 & 3,29 & 8,00 & 0,00 \\
\hline 14 & 45,19 & 0,00 & 11,94 & 17,13 & 5,57 & 4,44 & 2,51 & 3,22 & 10,00 & 0,00 \\
\hline 15 & 44,18 & 0,00 & 11,68 & 16,75 & 5,44 & 4,34 & 2,45 & 3,15 & 12,00 & 0,00 \\
\hline 16 & 46,19 & 0,00 & 12,21 & 17,51 & 5,69 & 4,54 & 2,56 & 3,29 & 4,00 & 4,00 \\
\hline 17 & 45,19 & 0,00 & 11,94 & 17,13 & 5,57 & 4,44 & 2,51 & 3,22 & 5,00 & 5,00 \\
\hline 18 & 44,18 & 0,00 & 11,68 & 16,75 & 5,44 & 4,34 & 2,45 & 3,15 & 6,00 & 6,00 \\
\hline 19 & 55,39 & 0,00 & 7,60 & 12,91 & 5,69 & 4,54 & 2,56 & 3,29 & 0,00 & 8,00 \\
\hline 20 & 54,19 & 0,00 & 7,44 & 12,63 & 5,57 & 4,44 & 2,51 & 3,22 & 0,00 & 10,00 \\
\hline 21 & 52,98 & 0,00 & 7,27 & 12,35 & 5,44 & 4,34 & 2,45 & 3,15 & 0,00 & 12,00 \\
\hline 22 & 55,39 & 0,00 & 7,60 & 12,91 & 5,69 & 4,54 & 2,56 & 3,29 & 8,00 & 0,00 \\
\hline 23 & 54,19 & 0,00 & 7,44 & 12,63 & 5,57 & 4,44 & 2,51 & 3,22 & 10,00 & 0,00 \\
\hline 24 & 52,98 & 0,00 & 7,27 & 12,35 & 5,44 & 4,34 & 2,45 & 3,15 & 12,00 & 0,00 \\
\hline 25 & 55,39 & 0,00 & 7,60 & 12,91 & 5,69 & 4,54 & 2,56 & 3,29 & 4,00 & 4,00 \\
\hline 26 & 54,19 & 0,00 & 7,44 & 12,63 & 5,57 & 4,44 & 2,51 & 3,22 & 5,00 & 5,00 \\
\hline 27 & 52,98 & 0,00 & 7,27 & 12,35 & 5,44 & 4,34 & 2,45 & 3,15 & 6,00 & 6,00 \\
\hline 28 & 40,21 & 2,68 & 15,59 & 19,03 & 6,18 & 4,93 & 7,79 & 3,57 & 0,00 & 0,00 \\
\hline 29 & 50,21 & 0,00 & 13,27 & 19,03 & 6,18 & 4,93 & 2,79 & 3,57 & 0,00 & 0,00 \\
\hline 30 & 60,21 & 0,00 & 8,27 & 14,03 & 6,18 & 4,93 & 2,79 & 3,57 & 0,00 & 0,00 \\
\hline
\end{tabular}




\subsection{Caracterização das mini- pelotas}

Na avaliação da qualidade das minipelotas, além da determinação química e granulométrica, foram utilizados ensaios de resistência à compressão, uma vez que se trata do desenvolvimento de um estudo fundamental para se verificarem a viabilidade técnica e as melhorias durante o manuseio e a sua utilização nos processos subseqüentes.

Os ensaios de resistência à compressão objetivam avaliar a resistência das minipelotas quando submetidas às ações mecânicas de carga atuantes durante o manuseio destas. Tal ensaio é destrutivo e cada pelota tem seu valor medido e representado pela média aritmética dos valores individuais determinados em kgf/pelota. O resultado final é apresentado na forma de um gráfico que mostra a resistência em função de diferentes períodos de cura das pelotas com auxílio do software SIMPEL.

\section{Resultados}

Os resultados podem ser interpretados das seguintes maneiras:

\subsection{Quanto ao tipo de aglomerante}

Atualmente são conhecidos modelos matemáticos que relacionam a resistência mecânica das pelotas com o tempo de cura para materiais aglomerantes. Assim sendo, espera-se que a curva resistência mecânica versus tempo de cura em dias tenha o formato mostrado na Figura 1.

Observa-se, na Figura 2, que, para os primeiros dias de cura, a resistência mecânica das pelotas cresce rapidamente, podendo esse trecho da curva ser substituído por uma reta com alto coeficiente angular. Assim sendo, como o tempo de cura analisado foi de apenas três dias, era de se esperar que os gráficos de resistência mecânica versus tempo de cura para as pelotas ensaiadas fossem semelhantes às retas crescentes, possuindo um alto coeficiente angular.
Observa-se, matematicamente, então, que alguns ensaios mostram-se concordantes com os modelos matemáticos atuais de cura de pelotas constituídas por materiais aglomerantes. Já outros ensaios apresentaram comportamento de materiais não-aglomerantes, como são os casos das Figuras 2 e 7, respectivamente.

Cabe ainda ressaltar que idealmente seriam necessários mais testes de cura e um maior tempo de cura para verificar a conclusão anterior, uma vez que a anomalia apresentada na Figura 7 pode ser temporária.

\subsection{Quanto à porcentagem de aglomerante}

Comparando-se quimicamente os ensaios 9 e 10, que possuem composição química equivalente dos aglomerados verifica-se que há maior presença de calcário calcítico fino reciclado da calcinação (RCAC) no teste 10 que no teste 9 .

Assim sendo, existe um forte indício que o resíduo denominado RCAC tem um comportamento não-aglomerante quando misturado em proporções mais elevadas aos demais resíduos. Verificou-se, também, que pode-se utilizar esse resíduo, se, juntamente a este, for utilizado o resíduo denominado cal recuperada em despoeiramento da calcinação (RCAL), desde que em proporções semelhantes.

\subsection{Quanto à porcentagem de pellet feed}

Sabe-se da literatura que:

- Quanto menor o tamanho médio das partículas, maior a resistência mecânica das pelotas.

- Quanto maior a distribuição granulométrica das partículas, maior a resistência mecânica das pelotas.

Assim sendo, pode-se afirmar que, de acordo com a granulometria das partículas, o melhor material para ser pelotizado é aquele que tem uma granulometria fina como seu tamanho médio e uma ampla distribuição granulométrica e, em virtude desse fato, quanto maior a quantidade de pellet feed na mistura menor a resistência das pelotas.

\subsection{Quanto às condições de cura}

Como as pelotas foram curadas de três maneiras diferentes (seca, úmida ao tempo e úmida no saquinho), foi estabelecida também, uma comparação entre esses tipos de cura, a fim de se determinar a melhor condição de cura para as pelotas.

Considerando, então, os ensaios 9 e 10, que obtiveram os melhores resultados em se tratando de resistência mecânica, têm-se as Figuras 2 até Figura 7, que mostram os gráficos de resistência mecânica para esses ensaios, bem como para cada tipo de cura.

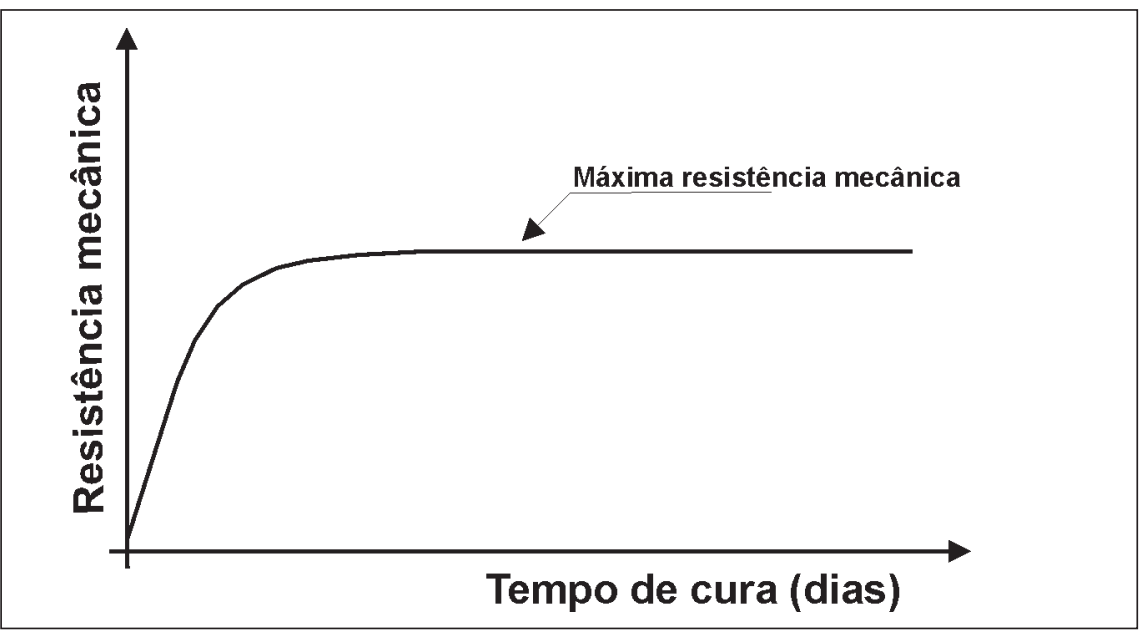

Figura 1 - Curva da resistência mecânica pelo tempo de cura em dias. 
Eduardo Reis de Oliveira et al.

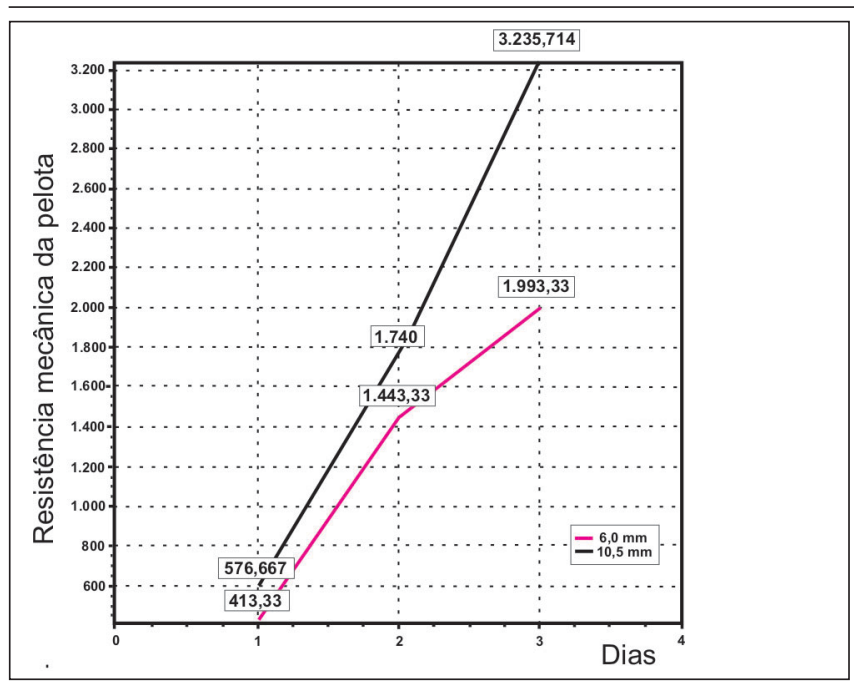

Figura 2 - Gráfico da resistência mecânica em função do tempo de cura para o ensaio 9 , condição de cura seca.

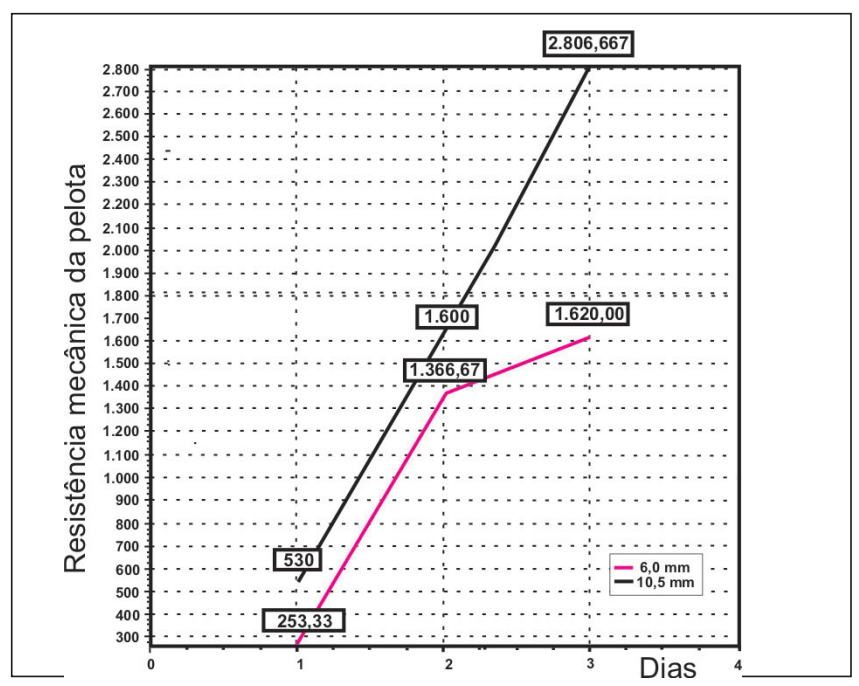

Figura 3 - Gráfico da resistência mecânica em função do tempo de cura para o ensaio 9, condição de cura úmida ao tempo.

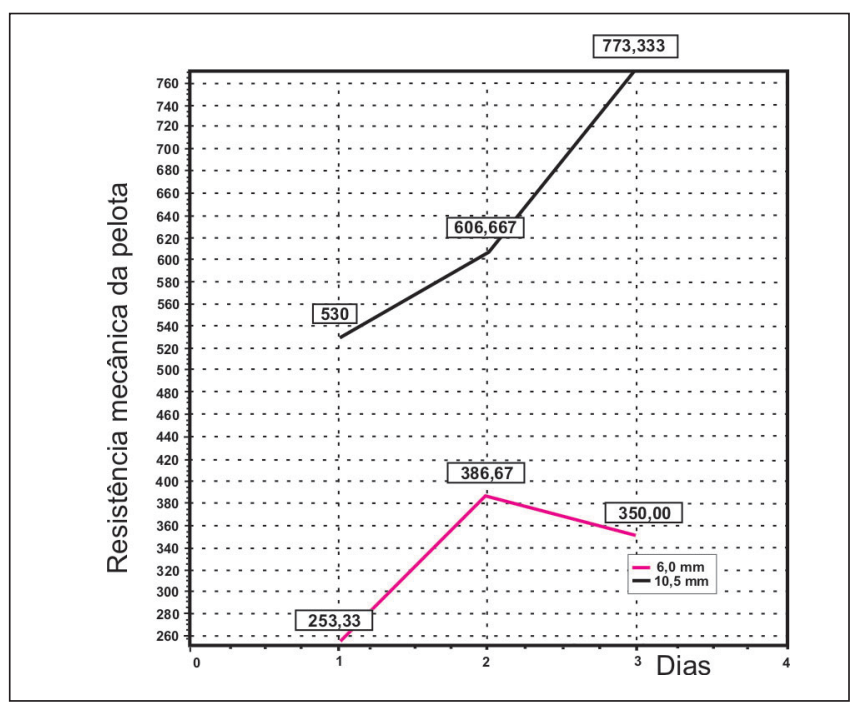

Figura 4 - Gráfico da resistência mecânica em função do tempo de cura para o ensaio 9 , condição de cura úmida no saquinho.

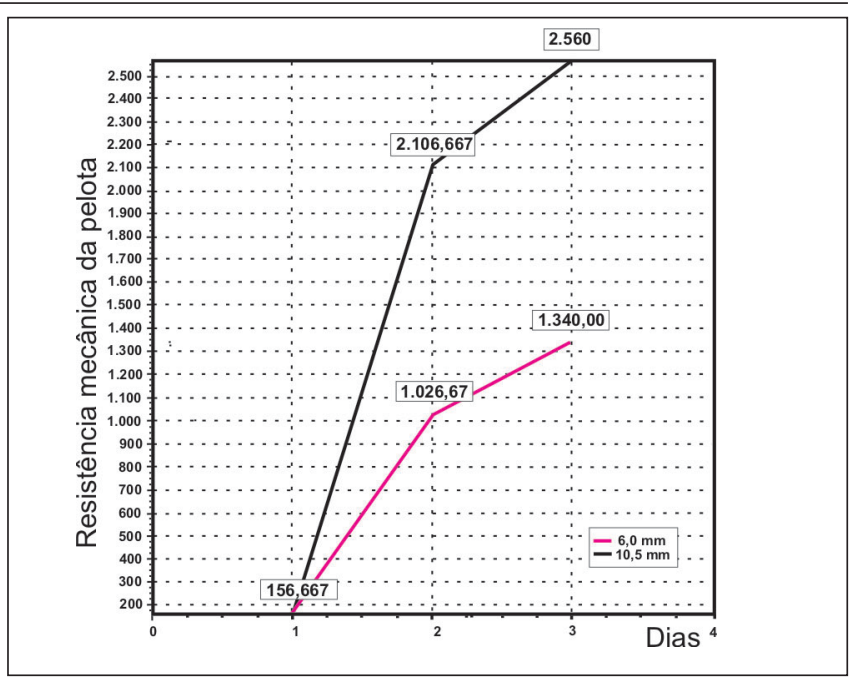

Figura 5 - Gráfico da resistência mecânica em função do tempo de cura para o ensaio 10 , condição de cura seca.

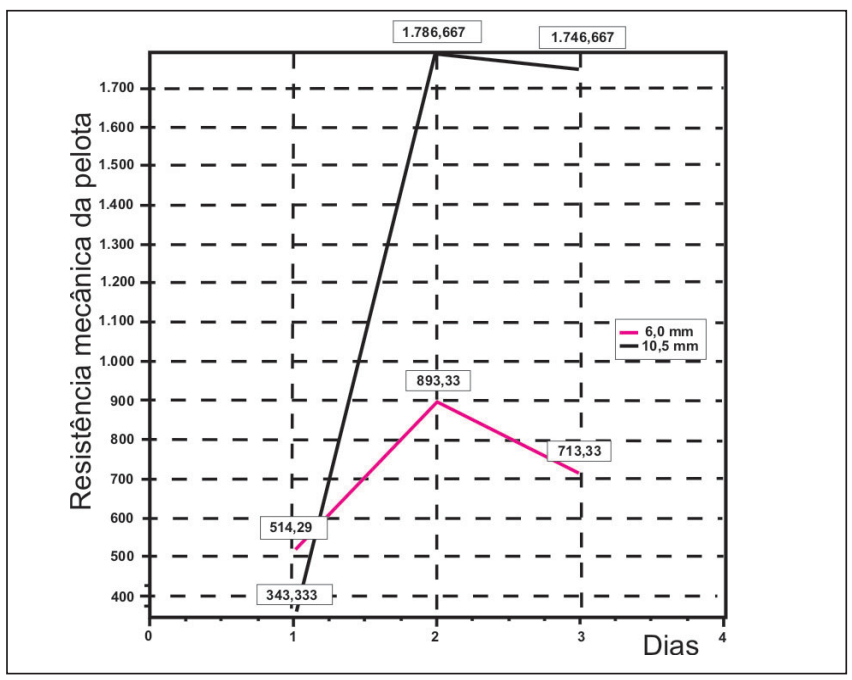

Figura 6 - Gráfico da resistência mecânica em função do tempo de cura para o ensaio 10, condição de cura úmida ao tempo.

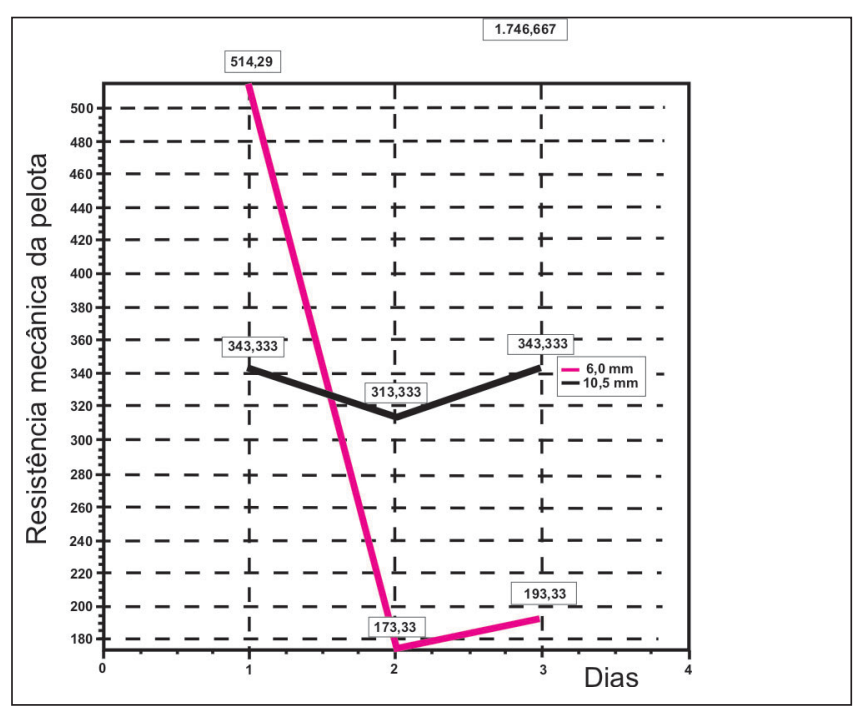

Figura 7 - Gráfico da resistência mecânica em função do tempo de cura para o ensaio 10 , condição de cura úmida no saquinho. 
Nota-se, claramente, que alguns desses ensaios têm característica aglomerante para determinado tipo de cura e característica não-aglomerante para outro tipo, como ocorre nos ensaios 9 e 10. Esses ensaios se comportam como aglomerantes nas condições de cura seca e úmida ao tempo, o que não ocorre na condição de cura úmida no saquinho.

Assim sendo, a condição de cura seca demonstra ser a mais abrangente e que a maioria dos ensaios tem comportamento aglomerante. Contudo, obteveram-se bons resultados utilizando a condição de cura úmida ao tempo, sendo que esta se mostra economicamente mais interessante, uma vez que as pelotas são curas sem a necessidade de nenhum cuidado adicional, como no caso das pelotas secas.

\subsection{Quanto ao erro experimental}

Uma vez que foi confeccionado apenas um lote de pelotas para cada mistura, pode-se ter cometido erros experimentais, tanto na confecção, quanto na cura das pelotas, erros estes que não podem ser determinados de maneira outra senão através da realização de mais lotes de pelotas.

Um fator indicativo da ocorrência de erros experimentais são os valores dos desvios-padrões calculados da resistência mecânica das pelotas. Os valores encontrados são mais altos que os esperados e isso pode-se dever a:

- Erros na confecção, cura e mesmo na quebra das pelotas.

- Heterogeneidade das pelotas devido a uma pelotização preferencial de certos materiais formando pelotas mais resistentes e uma posterior pelotização formando duas classes distintas de pelotas.

\section{Conclusões}

Conclui-se, então, que os resíduos apresentados a princípio como aglomerantes no presente trabalho apresentam tal característica, sendo que o grau aglomerativo depende da proporção de cada material na mistura a ser pelotizada, bem como do tipo de cura a ser adotado.

Assim sendo, as variações existentes na quantidade e na qualidade de tais materiais, não somente entre as diversas usinas, mas também em uma mesma usina, ao longo do tempo, devem ser sempre consideradas nos estudos de recuperação de pós e lamas em siderurgia.

Ainda além, tais misturas só podem ser pelotizadas com teores de umidade na faixa de 10 a $14 \%$.
Conclui-se, também, através dos testes brancos, que as misturas possuem outros constituintes com características aglomerativas.

Os resultados mostraram valores satisfatórios para o emprego das minipelotas na unidade de sinterização.

Elegeu-se, então, o ensaio 9 como sendo o melhor ensaio em matéria de resistência mecânica e o tipo de cura seca ao tempo como a melhor e economicamente mais interessante maneira de se curarem as pelotas produzidas.

\section{Agradecimentos}

À Companhia Siderúrgica de Tubarão (CST) e ao Programa de Pós-Graduação em Engenharia Mineral.

\section{Referências bibliográficas}

Na Internet: http://www.cst.com.br

ANDRADE, L. Processo de sinterização. Escola de Engenharia da UFMG, mar. 1992. (Monografia).

MARTINS, J. Avaliação do processo de pelotização a frio para minério de ferro. In: SEMINÁRIO COMIN/COMAP da ABM. Vitória: 1980.

Artigo recebido em 14/04/2003 e aprovado em 20/11/2003.

\title{
Simpósio Brasileiro de Exploração Mineral Braziliam Symposium on Mineral Exploration
}

\author{
Ouro Preto de 17 a 19 de maio de 2004
}

\author{
ADIMB - Agência para o Desenvolvimento Tecnológico da Indústria Mineral Brasileira \\ DNPM - Departamento Nacional da Produção Mineral \\ Ética Promoção de Eventos (Fone: 31 3444-4974 - Fax 31 3444-4329)
}

